\title{
Full-thickness macular hole after lamellar macular hole surgery: a case report
}

\author{
Marco Dutra Medeiros ${ }^{1}$, Micol Alkabes², Paolo Nucci², João Branco \\ ${ }^{1}$ Central Lisbon Hospital Center, Faculty of Medical Sciences, NOVA University of Lisbon, Lisbon - Portugal \\ ${ }^{2}$ University Eye Clinic, San Giuseppe Hospital, University of Milan, Milan - Italy
}

\begin{abstract}
Purpose: To describe a case of full-thickness macular hole (FTMH) after vitrectomy for lamellar hole (LH). Methods: Case report.

Results: The authors report a patient with progressive visual loss secondary to LH who developed FTMH following a vitrectomy repair. The postoperative findings as well as the clinical course after the second surgical approach are described.
\end{abstract}

Conclusions: Surgeons should be aware of this complication following LH surgical approach.

Keywords: Internal limiting membrane peeling, Lamellar macular hole, Macular hole, Pars plana vitrectomy

\section{Introduction}

Lamellar macular hole (LMH) was initially described by Gass (1) as a partial-thickness foveal defect believed to occur via interruption of the typical macular hole formation process or by the unroofing of the central fovea in chronic cystoid macular edema (CME).

This condition is characterized by an irregular foveal contour, rupture of the inner foveal surface, dissociation between the inner and the outer foveal layers, and absence of a full-thickness retinal defect with relative preservation of the foveal photoreceptors. Such lamellar defects likely have 3 different origins: tangential traction, anteroposterior traction, and degeneration in the setting of CME.

Spectral-domain optical coherence tomography (SD-OCT) is a simple and reliable means of diagnosis of $\mathrm{LMH}$ and allows us to distinguish it from similar, yet distinct, entities such as macular pseudohole (MPH), foveal pseudocysts, and fullthickness macular holes (FTMH). This distinction is important since it involves several different pathogenesis as well as distinct surgical approaches.

In contrast to the natural history of FTMH, progression of $\mathrm{LMH}$ is very slow and these patients uncommonly progress to

Accepted: April 28, 2014

Published online: May 17, 2014

Corresponding author:

Marco Dutra Medeiros, MD

Central Lisbon Hospital Center

Faculty of Medical Sciences

NOVA University of Lisbon

José António Serrano St

1150-199 Lisbon, Potugal

marcodutramedeiros@gmail.com more severe levels of visual deficit.

Nevertheless, there is a subset of patients with $\mathrm{LMH}$ who do progress to significant levels of central visual disturbance. Treatment in these instances remains controversial. Given such a clinical evolution, one can debate whether it is worthwhile to attempt surgical treatment.

There are several reports of LMH surgical treatment with vitrectomy. Few complications of this surgical procedure have been reported, mainly regarding the hypothetical development of FTMH after LMH repair. Few cases have been described in the literature addressing this issue (2-8).

We report a case of a patient with progressive visual loss secondary to LMH who developed a FTMH following a vitrectomy repair. We emphasize the postoperative findings as well as the clinical course after the second surgical approach.

\section{Case report}

A 77-year-old man with unremarkable systemic history was referred to our hospital. He complained of decreased vision in his left eye as well as a history of metamorphopsia for approximately 5 months. He did not report any trauma. His best-corrected visual acuity (BCVA) was 20/20 in the right eye and 20/63 in the left eye. Anterior segment examination revealed no further abnormalities, beyond his bilateral pseudophakic status. Funduscopy revealed an image of a lamellar hole that was confirmed by Spectralis ${ }^{\circledR}$ SD-OCT (Heidelberg Spectralis; Heidelberg Engineering, Heidelberg, Germany).

On SD-OCT scan, we observed an LMH (Fig. 1), according to the Witkin et al (2) criteria: rupture of the inner retina, intraretinal dissociation (localized or circumferential around the hole), and relative sparing of foveal photoreceptors. Beyond that, an epiretinal membrane was present on the temporal side of the fovea and skirts along the superior and nasal aspect of the macula. We have taken into consideration 


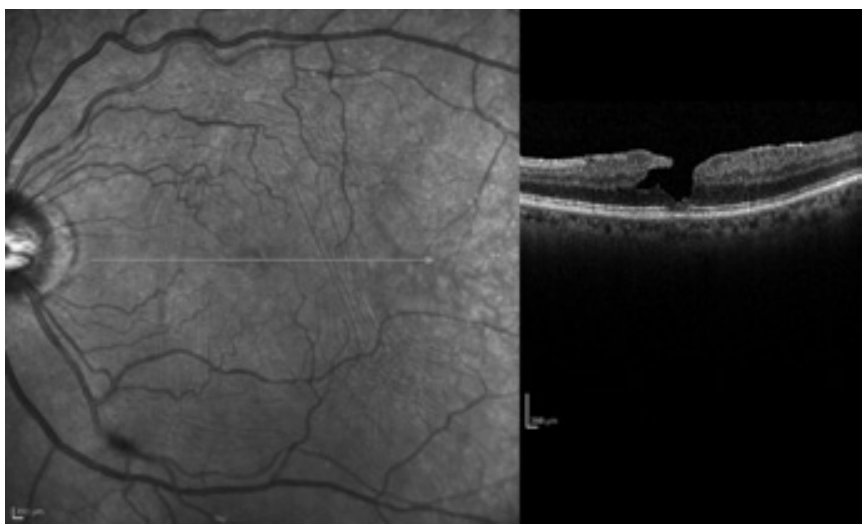

Fig. 1 - Spectralis spectral-domain optical coherence tomography image demonstrates all 4 criteria for the diagnosis of a lamellar hole: an irregular foveal contour, break in the inner fovea, separation of the inner from the outer foveal retinal layers, and absence of a full-thickness foveal defect with intact foveal photoreceptors. Furthermore, an epiretinal membrane is present on the temporal side of the fovea and skirts around the superior and nasal aspect of the macula. The posterior hyaloid is detached from the macula.

the OCT criteria of Witkin et al (2) because they best account for the various anatomical presentations of LMH. Nonetheless, we are not sure that the photoreceptors are truly intact because we find a slight irregularity of the photoreceptor layer in our OCT image.

The surgical procedure was proposed due to the symptomatic visual loss associated with significant metamorphopsia complaints.

Surgery was performed under local anesthesia with a peribulbar block of lidocaine and bupivacaine. Visualization during vitrectomy was achieved with a noncontact wide-angle system (BIOM II; Oculus Optikgeräte $\mathrm{GmbH}$, Wetzlar-Dutenhofen, Germany). The patient underwent standard 3-port vitrectomy by one of the authors (J.B.) with careful attention directed to separation and complete removal of the posterior hyaloid. Epiretinal membrane (ERM) peeling was accomplished with the aid of trypan blue solution (MembraneBlue ${ }^{\circledR}$, DORC International, Zuidland, the Netherlands). Fluid-air exchange was carried out and air in the vitreous cavity was replaced with $20 \%$ sulfur hexafluoride gas. Any operative complication was noted. The patient was instructed to maintain a prone position for 5 days after surgery.

A FTMH developed and was documented on SD-OCT performed on postoperative day 10 (Fig. 2). According to this anatomical unsuccessful outcome, the patient underwent another surgical procedure. Then we proceeded to a widened internal limiting membrane (ILM) peeling beyond the temporal vascular arcades assisted by Brilliant Blue $G$ (Brilliant Peel; DORC International) dye to stain and enhance complete ILM removal. An additional Brilliant Blue $\mathrm{G}$ injection was administered to visualize any remaining ILM in the macular region. Gas tamponade $\left(14 \% \mathrm{C}_{3} \mathrm{~F}_{8}\right)$ was injected at the end of surgery. The patient again adopted postoperative 5-day face-down positioning.

One month later, SD-OCT scans revealed a fully closed macular hole (Fig. 3). We observed a slight distortion of outer retinal layers with elevation of the external limiting membrane, the ellipsoid, and cone outer segment tips lines.

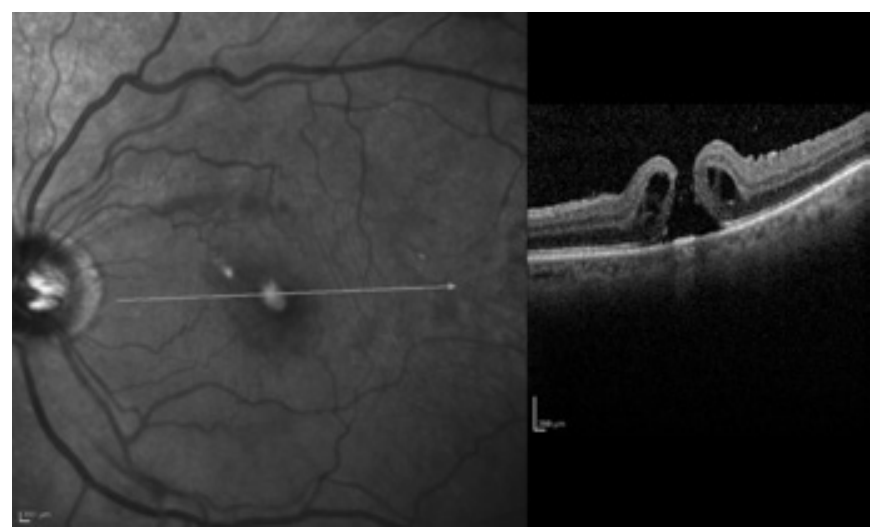

Fig. 2 - Postoperative Spectralis spectral-domain optical coherence tomography image. The patient underwent a pars plana vitrectomy with peeling of the posterior hyaloid from the fovea, air/fluid exchange, and sulfur hexafluoride $20 \%$ injection. The patient subsequently developed a full-thickness macular hole.

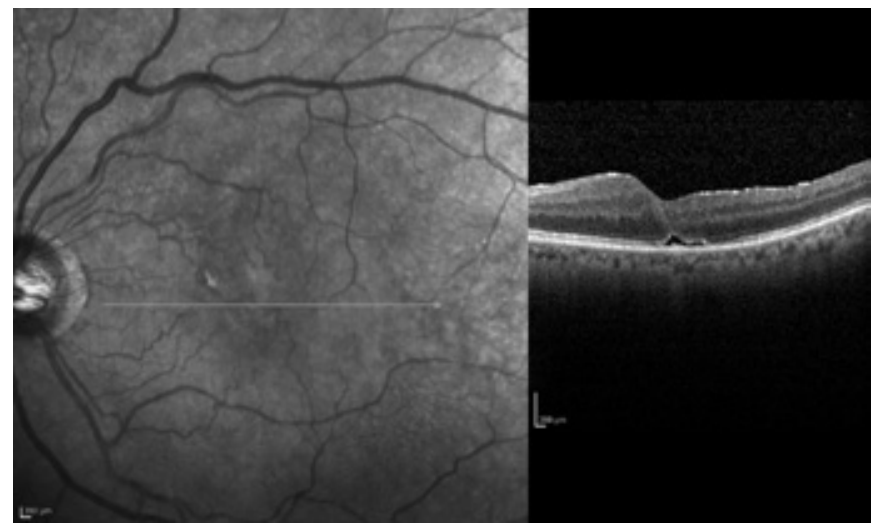

Fig. 3 - Postoperative Spectralis spectral-domain optical coherence tomography (SD-OCT) image. The patient underwent a second vitrectomy procedure with a widened internal limiting membrane (ILM) peeling beyond the temporal vascular arcades. One month later, SD-OCT scans revealed a fully closed macular hole. We observed a slight distortion of outer retinal layers with elevation of the external limiting membrane, the ellipsoid and cone outer segment tips lines.

Six months later, the left eye BCVA improved to 20/32. The patient reported a symptomatic improvement regarding to the previous visual complaints. An SD-OCT examination showed the restoration of a normal foveal contour.

\section{Discussion}

Lamellar macular hole is an acquired macular anomaly characterized by central foveal thinning with a variable level of central visual distortion and acuity loss. This entity may represent the result of several different clinical conditions, and it is not always easy to determine the etiology of a particular LMH. Optical coherence tomography imaging currently provides the gold standard for detecting $\mathrm{LMH}$ and distinguishing it from other vitreomacular interface disorders. 
Proper differential diagnosis with $\mathrm{MPH}$ should be taken into account, due to several similarities. Clinical differentiation between LMH and MPH may be tricky. For instance, visual acuities may be normal, or mildly impaired, being around 20/40. Moreover, Amsler grid and Watzke-Allen are often negative. In addition, ERMs, which were initially thought to be strongly associated with $\mathrm{MPH}$, have a high prevalence in patients with $\mathrm{LMH}$. Moreover, the majority of patients with LMH keep a reasonable central vision of 20/40 or better, and surgical intervention remains controversial.
In patients with significant visual loss, published reports of surgical intervention are limited and have uneven final outcomes (Tab. I). Some authors believe that there is no proof that surgical intervention is helpful, whereas other studies (3-5) found vitrectomy with ERM-ILM removal to be beneficial regarding the functional and anatomical outcome.

Up to now, one of the largest studies published (27 eyes) performed by Garretson et al (4) found vitrectomy beneficial for $93 \%$ of their patient cohort, with a mean gain of 3 Snellen lines of visual acuity.

TABLE I - Published clinical studies regarding surgical intervention in patients with lamellar macular hole

\begin{tabular}{|c|c|c|c|c|c|}
\hline $\begin{array}{l}\text { Author } \\
\text { (year) }\end{array}$ & Purpose & Study design & $\begin{array}{l}\text { Outcome } \\
\text { measures }\end{array}$ & $\begin{array}{l}\text { Number } \\
\text { of eyes }\end{array}$ & Results \\
\hline Lee (2012) (8) & $\begin{array}{l}\text { To determine long-term } \\
\text { surgical findings and } \\
\text { outcomes after vitrectomy } \\
\text { for symptomatic LMH }\end{array}$ & $\begin{array}{l}\text { Retrospective } \\
\text { interventional } \\
\text { case series }\end{array}$ & $\begin{array}{l}\text { BCVA, foveal } \\
\text { structure }\end{array}$ & 31 & $\begin{array}{l}\text { Final BCVA improved more than } 2 \text { lines } \\
\text { postoperatively in } 18 \text { eyes (58.1\%) leading to } \\
\text { a mean gain of } 0.18 \text { logMAR visual acuity; } 28 \\
\text { eyes ( } 90.3 \%) \text { improved or normalized in foveal } \\
\text { appearance on postoperative OCT images of } \\
\text { the macula }\end{array}$ \\
\hline $\begin{array}{l}\text { Casparis } \\
(2011)(7)\end{array}$ & $\begin{array}{l}\text { To assess functional results } \\
\text { of surgical treatment } \\
\text { of LMH associated with } \\
\text { epiretinal membrane }\end{array}$ & $\begin{array}{l}\text { Retrospective } \\
\text { interventional } \\
\text { case series }\end{array}$ & BCVA & 44 & $\begin{array}{l}\text { Mean logMAR visual acuity improved from } \\
0.4 \text { preoperatively to } 0.13 \text { postoperatively } \\
(p=0.0001) \text {; no patient lost vision }\end{array}$ \\
\hline $\begin{array}{l}\text { Parolini et al } \\
\text { (2011) (3) }\end{array}$ & $\begin{array}{l}\text { To correlate clinical and } \\
\text { OCT with morphologic } \\
\text { and immunohistochemical } \\
\text { findings of ERMs in LMHs }\end{array}$ & $\begin{array}{l}\text { Prospective } \\
\text { interventional } \\
\text { case series }\end{array}$ & $\begin{array}{l}\text { BCVA, } \\
\text { morphologic } \\
\text { and immuno- } \\
\text { histochemical } \\
\text { findings of ERM }\end{array}$ & 19 & $\begin{array}{l}\text { Morphologic components differ in epiretinal } \\
\text { cell proliferations of LMHs; surgery resulted in } \\
\text { significant improvement (74\%) of BCVA, with } \\
\text { a mean gain of } 2 \text { Snellen lines in both groups; } \\
3 \text { patients (16\%) developed a FTMH defect } \\
\text { requiring additional surgery }\end{array}$ \\
\hline
\end{tabular}

Michalewska To present functional and (2010) (6) anatomical results of PPV without gas tamponade in $\mathrm{LMH}$; additionally, the study determined factors influencing final outcome

Androudi et al To categorize tomographi(2009) (5) cally the distinct entity of LMH and present the surgical outcomes

Garretson et al To investigate the surgical (2008) (4) findings and outcomes after vitrectomy for a $\mathrm{LMH}$
Prospective BCVA, foveal interventional structure case series

\section{Prospective BCVA, foveal} interventional structure case series

Retrospective BCVA, foveal
interventional structure case series
Prior to surgery, mean visual acuity was 0.2 ; 12 months after surgery, the mean visual acuity was 0.51 ; lower visual acuity was observed in patients with photoreceptor layer defects localized under the fovea

Postoperatively, BCVA improved in 17 out of the 20 cases (85\%) operated from the first group of patients; mean BCVA improvement in the first group was 2.6 Snellen lines, which was statistically significant

27 BCVA improved postoperatively in 25 of 27 eyes (93\%), with a mean improvement of 3.2 Snellen lines; OCT images were obtained and were judged to have improved or normalized in 22 of 24 (92\%) of these patients

19 Criteria for the OCT diagnosis of a lamellar hole were as follows: (1) irregular foveal contour; (2) break in the inner fovea; (3) intraretinal split; and (4) intact foveal photoreceptors; vitrectomy was anatomically and visually successful in only 1 of 4 patients

$\begin{array}{ll}\text { Witkin } & \text { To evaluate OCT criteria for } \\ \text { (2005) (2) } & \text { the diagnosis of a LMH and } \\ & \text { to increase understanding of } \\ & \text { lamellar hole pathogenesis } \\ & \text { by examining fine anatomic } \\ & \text { features using SD-OCT }\end{array}$

Retrospective observational case series ultra-high- resolution OCT images
Standard and es


Reported complications are scarce, mainly regarding the evolving process to FTMH appearance. So far, there are only 2 studies describing this sort of complication. Witkin et al (2) described 4 patients who had undergone vitrectomy for $\mathrm{LMH}$ with only 1 case having achieved anatomic and visual success. Two of their patients developed FTMH after vitrectomy. In Parolini et al (3), 3 of 10 patients (15.8\%) developed FTMH after LMH surgery, thereby requiring additional surgery.

In our case, a question arises about the pathogenesis concerning the FTMH formation following a LMH first surgical approach. To our knowledge, there are no published articles regarding etiopathogenesis.

Earlier theories of FTMH formation include the suggestions that its development is caused by tangential vitreomacular traction (Gass 1995 (9)) or cystoid degeneration of foveal inner retinal layers. More recently, further studies using OCT suggest that vitreofoveal traction plays a major role in the pathogenesis of macular hole.

Macular hole formation after vitrectomy has been reported and the mechanism is unknown. The primary effect of vitrectomy is to relieve vitreous traction involving the macula. Hence, FTMH emergence in an eye that has previously undergone vitrectomy seems contradictory.

Several theories of pathophysiology addressing the development of FTMH following vitrectomy for retinal detachment surgery have been formulated, including tangential traction by remnant vitreous, the ILM, or an ERM arising (10). None of those conditions occurred soon after surgery in our case.

Conversely, one can postulate that during intrasurgical dynamics and subsequent induction of posterior vitreous detachment, the transmission of anteroposterior mechanical forces might induce significant vitreous traction at the fovea with subsequent FTMH formation. We suspect this is the case in our patient.

We highlight successful anatomical FTMH closure after a second surgical procedure with an ILM peeling, achieving significant functional improvement. The prognosis is better compared with postoperative anatomical and functional outcomes in high myopic macular hole (11).

In conclusion, surgeons should be aware of this complication following LMH surgical approach and should take into account all the variables related to intraoperative vitreous dynamics.

\section{Disclosures}

Financial support: No financial support was received for this submission.

Conflict of interest: None of the authors has conflict of interest with this submission.

\section{References}

1. Gass JD. Lamellar macular hole: a complication of cystoid macular edema after cataract extraction: a clinicopathologic case report. Trans Am Ophthalmol Soc. 1975;73:231-50.

2. Witkin AJ, Ko TH, Fujimoto JG, et al. Redefining lamellar holes and the vitreomacular interface: an ultrahigh-resolution optical coherence tomography study. Ophthalmology 2006;113: 388-97.

3. Parolini B, Schumann RG, Cereda MG, Haritoglou C, Pertile G. Lamellar macular hole: a clinicopathologic correlation of surgically excised epiretinal membranes. Invest Ophthalmol Vis Sci. 2011;52(12):9074-83.

4. Garretson BR, Pollack JS, Ruby AJ, Drenser KA, Williams GA, Sarrafizadeh R. Vitrectomy for a symptomatic lamellar macular hole. Ophthalmology 2008;115:884-886.

5. Androudi S, Stangos A, Brazitikos PD. Lamellar macular holes: tomographic features and surgical outcome. Am J Ophthalmol. 2009;148(3):420-6.

6. Michalewska Z, Michalewski J, Odrobina D, Pikulski Z, Cisiecki S, Dziegielewski K, Nawrocki J. Surgical treatment of lamellar macular holes. Graefes Arch Clin Exp Ophthalmol. 2010;248(10):1395-400.

7. Casparis H, Bovey EH. Surgical treatment of lamellar macular hole associated with epimacular membrane. Retina. 2011;31(9): 1783-90.

8. Lee SJ, Jang SY, Moon D, Choi KS, Jung GY. Long-term surgical outcomes after vitrectomy for symptomatic lamellar macular holes. Retina. 2012;32(9):1743-8.

9. Gass JDM (1995): Reappraisal of biomicroscopic classification of stages of development of a macular hole. Am J Ophthalmol. 119:752-759.

10. Rahman W, Georgalas I, da Cruz L. Macular hole formation after vitrectomy for retinal detachment. Acta Ophthalmol. 2010;88:e147-8.

11. Alkabes $M$, Pichi F, Nucci $P$, et al. Anatomical and visual outcomes in high myopic macular hole (HM-MH) without retinal detachment: a review. Graefes Arch Clin Exp Ophthalmol. 2014;252(2):191-9. 
Copyright of European Journal of Ophthalmology is the property of Wichtig International Limited and its content may not be copied or emailed to multiple sites or posted to a listserv without the copyright holder's express written permission. However, users may print, download, or email articles for individual use. 